\title{
Early Arterial Lesions in Maturity Onset Diabetes Mellitus Detected by an Ultrasonic Technique
}

\author{
S. A. Cairns ${ }^{1}$, J. P. Woodcock, and A. J. Marshall \\ Bristol Royal Infirmary and Department of Medical Physics, Bristol General Hospital, Bristol, England
}

\begin{abstract}
Summary. Using an ultrasonic technique preclinical atheroma was studied in maturity onset diabetics. The elasticity of the leg arteries was measured as the elastic modulus in 32 patients and a normal range was established in 13 controls. The elastic modulus was higher (i. e. the arteries were stiffer) in diabetics than controls and this was associated with a higher mean blood pressure in the diabetics. Nine phenformin and 10 chlorpropamide treated diabetics had evidence of more severe arterial disease than 13 diet treated patients. This could not be accounted for by other factors known to influence arterial disease.
\end{abstract}

Key words: Maturity onset diabetes mellitus, oral hypoglycaemic agents, atherosclerosis, ultrasonic Doppler velocimeter, pulse wave velocity, elastic modulus.

Diabetics develop atherosclerosis earlier than nondiabetics and cardiovascular disease is a major cause of morbidity and mortality in diabetes mellitus [1]. Studies of the natural history of arterial disease in diabetes are limited by clinical, radiological and pathological techniques which allow detection only of advanced disease $[2,3,4,5]$. Ultrasonic measurement of pulse wave velocity (P.W.V.) is a sensitive indicator of early arterial damage [6] and we have used the technique to study preclinical changes in the leg arteries of maturity onset diabetics. In this pilot study normal controls, patients on diet alone

1 Present address: Tutor in Medicine, Manchester Royal Infirmary, Manchester M13 9WL. and patients taking a sulphonylurea (chlorpropamide) and a biguanide (phenformin) are compared.

\section{Patients and Methods}

Thirty-two maturity onset diabetics, 22 male and 10 female, age range 45-65 years and 13 normal subjects, 8 male and 5 female, age range 50-65 years were studied. All the diabetics had been diagnosed more than two years previously and in each case their treatment regime had been unchanged for at least 18 months. All the females studied were postmenopausal. Subjects with diseases other than diabetes or on drugs other than oral hypoglycaemic agents were excluded. No subject had clinical evidence of peripheral arterial disease. Thirteen of the diabetics were on carbohydrate restricted diet alone, 9 were being treated with phenformin, dose range $50-100 \mathrm{mg}$ per day and diet, and 10 with chlorpropamide, dose range $250-500 \mathrm{mg}$ per day and diet.

Clinical assessment of the subjects included a smoking history, recording of height and weight, measurement of supine blood pressure (B.P.) expressed as mean B.P. =

systolic +2 diastolic pressure,

3

and examination for diabetic retinopathy and peripheral neuropathy. A subject was considered to be a smoker if he smoked more than 5 cigarettes per day. Weight was expressed as percentage of ideal body weight derived from the Metropolitan Life Assurance Co. Obesity Statistics [7]. Peripheral neuropathy was taken to be present when there was cutaneous sensory loss or when vibration sense and 
Table 1. Comparison of all diabetics and diabetic treatment groups with normal subjects

\begin{tabular}{|c|c|c|c|c|}
\hline & \multirow{2}{*}{$\begin{array}{l}\text { All diabetics } \\
(32)\end{array}$} & \multicolumn{3}{|c|}{ Diabetic treatment groups } \\
\hline & & Diet (13) & $\begin{array}{l}\text { Chlor- } \\
\text { propamide (10) }\end{array}$ & Phenformin (9) \\
\hline \multicolumn{5}{|l|}{ Sex distribution } \\
\hline \multicolumn{5}{|l|}{ Male : Female } \\
\hline Diabetics & $22: 10$ & $10: 3$ & $7: 3$ & $5: 4$ \\
\hline Normals (13) & $8: 5$ & $8: 5$ & $8: 5$ & $8: 5$ \\
\hline $\mathrm{P}$ & NS & NS & NS & NS \\
\hline \multicolumn{5}{|l|}{ Mean age } \\
\hline \multicolumn{5}{|l|}{ Years \pm SEM } \\
\hline Diabetics & $57.8 \pm 1.0$ & $58.8 \pm 1.4$ & $56.8 \pm 1.7$ & $57.4 \pm 2.5$ \\
\hline Normals (13) & $56.3 \pm 1.3$ & $56.3 \pm 1.3$ & $56.3 \pm 1.3$ & $56.3 \pm 1.3$ \\
\hline $\mathbf{P}$ & NS & NS & NS & NS \\
\hline \multicolumn{5}{|l|}{ Smokers } \\
\hline Diabetics & 7 & 3 & 4 & 0 \\
\hline Normals (13) & 4 & 4 & 4 & 4 \\
\hline $\mathrm{P}$ & NS & NS & NS & NS \\
\hline \multirow{2}{*}{\multicolumn{5}{|c|}{$\begin{array}{l}\text { Mean } \% \text { of ideal } \\
\text { body weight } \pm \text { SEM }\end{array}$}} \\
\hline & & & & \\
\hline Diabetics & $104.3 \pm 2.8$ & $103.8 \pm 3.1$ & $103.8 \pm 7.2$ & $105.4 \pm 3.9$ \\
\hline Normals (13) & $93.2 \pm 2.9$ & $93.2 \pm 2.9$ & $93.2 \pm 2.9$ & $93.2 \pm 2.9$ \\
\hline $\mathrm{P}$ & NS & NS & NS & NS \\
\hline \multicolumn{5}{|c|}{ Mean B.P. mm Hg. \pm SEM } \\
\hline Diabetics & $120 \pm 1.9$ & $119 \pm 3.6$ & $122 \pm 3.8$ & $120 \pm 2.0$ \\
\hline Normals (13) & $109 \pm 3.5$ & $109 \pm 3.5$ & $109 \pm 3.5$ & $109 \pm 3.5$ \\
\hline $\mathrm{P}$ & $<0.01$ & NS & $<0.05$ & $<0.05$ \\
\hline \multicolumn{5}{|c|}{ Mean elastic modulus } \\
\hline \multicolumn{5}{|c|}{ N.m ${ }^{-2} \times 10^{5} \pm S E M$} \\
\hline Diabetics & $1.66 \pm 0.1$ & $1.50 \pm 0.12$ & $1.84 \pm 0.17$ & $1.74 \pm 0.23$ \\
\hline Normals (13) & $1.34 \pm 0.06$ & $1.34 \pm 0.06$ & $1.34 \pm 0.06$ & $1.34 \pm 0.06$ \\
\hline $\mathrm{P}$ & $<0.01$ & NS & $<0.01$ & $<0.05$ \\
\hline $\begin{array}{ll}(\text { ) } & =\text { No. of } \\
\text { SEM } & =\text { standa } \\
\text { NS } & =\text { not sig }\end{array}$ & & & & \\
\hline
\end{tabular}

the tendon jerk were absent at the ankle or when one of these was lost at the knee and ankle. An E.C.G. was recorded and fasting blood sugar, fasting serum cholesterol and triglycerides measured in each diabetic subject.

The P.W.V. was measured in both legs of each subject using ultrasonic Doppler velocimeters placed simultaneously at femoral and posterior tibial pulses. The signals were recorded on magnetic tape and visualised using an audio-spectrum analyser (sonagram). From the foot of each waveform on this sonagram the femoral-posterior tibial pulse time delay was measured by an operator who was unaware of the patients' treatment. From this, having measured the leg length in each case, the P.W.V. was calculated. This pulse propagation velocity is related to the elastic properties of the arteries of the leg by: P.W.V. $=(\mathrm{K} / \varrho)^{1 / 2}$ where $\varrho$ is the density of blood, taken as $1050 \mathrm{~kg} \cdot \mathrm{m}^{-3}$, and $\mathrm{K}$ the volume distensibility elastic modulus of the artery wall per unit length of vessel. $\mathrm{K}$ was calculated from a knowledge of
P.W. V. and $\varrho$. A rising elastic modulus indicates increasing stiffness of the arterial wall.

Statistical analysis of results was by Student's $\mathrm{t}$ test and $\chi^{2}$ test where appropriate. Statistical significance was taken to have been achieved at the $5 \%(\mathrm{P}<0.05)$ level.

\section{Results}

The normal subjects' mean age, sex distribution, mean \% ideal body weight and smoking habits were not significantly different from the diabetics'. Mean B.P. was higher in diabetics than normals. Of the three diabetic treatment groups only the diet treated group did not have a significantly higher B.P. than the control group (Table 1). There was no statistically significant difference in the age distribution of the controls, the diabetics as a whole or the diabetic treatment groups (Table 2). The three diabetic treatment groups are compared in Table 3. No sig- 
nificant differences were detected between the groups in any of the parameters listed.

The diabetics as a whole had a higher mean elastic modulus than the controls and of the three treatment subgroups only the elastic modulus of the diet treated group was not significantly higher than the control group (Table 1). The phenformin and chlorpropamide treated groups had a higher elastic modulus than the diet treated group but the difference was only significant for chlorpropamide (Table 4).

The regression line derived from 28 measurements of elastic modulus in 13 normal subjects (i. e. both legs from each subject) is plotted against mean blood pressure in Figure 1. Two standard deviations above this line is taken as the upper limit of normality. All control measurements fall below this limit. Two of 26 measurements in the diet treated group are abnormal while five of 16 in the phenformin and six of 16 in the chlorpropamide treated group are abnormal. For technical reasons the P. W. V. could not be accurately measured from the sonagram in one leg of each of two phenformin and four chlorpropamide treated patients. There was a significantly higher proportion of abnormal limbs in each of the drug treated groups compared to diet (Table 5).

\section{Discussion}

The technique by which P.W.V. is measured is well established. The measurement is highly reproducible [8] and is not affected by obesity of the limb. Various parameters of arterial elasticity including the elastic modulus may be calculated from it [6]. The elastic modulus increases with mean B.P. [9] and we have taken this into account in deriving the limits of normality in our study. Arterial wall elasticity (i. e. arterial stiffness) increases steadily with age $[6,10]$. This rise correlates with changes in the tunica media of the artery [11] and with the development of atherosclerosis [12]. The change in the elastic modulus-mean blood pressure characteristic is very marked in early atheroma [12] and therefore ultrasonic techniques have been proposed as screening tests for atheroma [10]. The method we have used can, therefore, be expected to detect the early changes of degenerative arterial disease and offers a quantitative measurement of the degree of change. The technique is atraumatic and quickly and simply performed.

The elastic modulus of our diabetics was significantly higher than our controls. The only other difference between the two groups was a significantly higher B.P. in the diabetics. In the only treatment subgroup, the diet treated, in which mean elastic
Table 2. Age distribution of normal controls, all diabetics and subjects in the three diabetic treatment groups. There was no significant difference in age distribution between any of the five groups

\begin{tabular}{|c|c|c|c|c|c|}
\hline & \multicolumn{5}{|c|}{ Age (years) } \\
\hline & $40-49$ & $50-54$ & $55-59$ & $60-65$ & Total \\
\hline Normals & 0 & 4 & 5 & 4 & 13 \\
\hline $\begin{array}{l}\text { All diabetics } \\
\text { Diet }\end{array}$ & 3 & 4 & 11 & 14 & 32 \\
\hline $\begin{array}{l}\text { treated diabetics } \\
\text { Chlorpropamide }\end{array}$ & 0 & 2 & 4 & 7 & 13 \\
\hline $\begin{array}{l}\text { treated diabetics } \\
\text { Phenformin }\end{array}$ & 1 & 1 & 5 & 3 & 10 \\
\hline
\end{tabular}

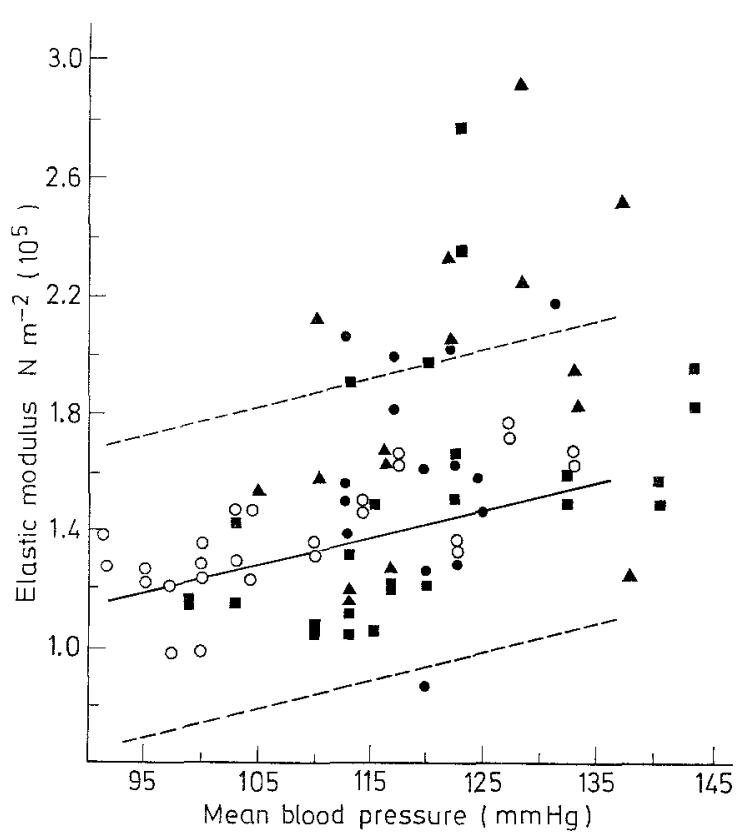

Fig. 1. Graph of Elastic Modulus against mean blood pressure for diabetics controlled by diet $(\boldsymbol{D})$, chlorpropamide $(\mathbf{A})$ and phenformin $(\bullet)$, and normals within the same age range $(O)$. The regression line for normals is given by Elastic Modulus $\times 10^{5}$ $=0.0019 \times$ Mean Blood Pressure +1.14 , the stippled lines are $\pm 2 \mathrm{SD}$ of the mean. (Correlation coefficient $\mathrm{r}=0.92$ )

modulus did not significantly differ from controls, neither did the B.P. An association between diabetes and hypertension is well documented $[13,14]$. Common factors in the population may raise both blood sugar and blood pressure [15] and it has been suggested that a raised $B . P$. is the cause of the increased incidence of atheroma in diabetics [14].

No differences in blood pressure or other parameter known to influence arterial disease were detected between our three treatment groups. Yet the chlorpropamide treated group had a significantly 
Table 3. Comparison of characteristics of diabetic patients treated with diet, phenformin and chlorpropamide. No significant difference between treatment groups for any parameter

\begin{tabular}{llcllll}
\hline & $\begin{array}{l}\text { Age } \\
\text { years }\end{array}$ & Males & $\begin{array}{l}\text { Duration } \\
\text { D.M. } \\
\text { years }\end{array}$ & $\begin{array}{l}\text { Duration } \\
\text { treatment } \\
\text { years }\end{array}$ & $\begin{array}{l}\text { \% of ideal } \\
\text { weight }^{\mathrm{a}}\end{array}$ & $\begin{array}{l}\text { Mean BP } \\
\mathrm{mm} \mathrm{Hg}^{\mathrm{a}}\end{array}$ \\
\hline Diet (13) & $58.8 \pm 1.4$ & 10 & $6.5 \pm 1.1$ & $6.0 \pm 1.0$ & $103.8 \pm 3.1$ & $119 \pm 3.6$ \\
Phenformin (9) & $57.4 \pm 2.5$ & 5 & $8.2 \pm 2.3$ & $5.1 \pm 1.0$ & $105.4 \pm 3.9$ & $120 \pm 2$ \\
Chlorpropamide (10) & $56.8 \pm 1.7$ & 7 & $7.1 \pm 0.9$ & $6.4 \pm 0.9$ & $103.8 \pm 7.2$ & $122 \pm 3.8$ \\
\hline
\end{tabular}

\begin{tabular}{llllllll}
\hline & Smokers & $\begin{array}{l}\text { Peripheral } \\
\text { neuropathy }\end{array}$ & $\begin{array}{l}\text { Diabetic } \\
\text { retinopathy }\end{array}$ & $\begin{array}{l}\text { Ischaemic } \\
\text { heart disease } \\
\text { (ECG changes) }\end{array}$ & $\begin{array}{l}\text { Fasting blood } \\
\text { sugar } \\
\text { mmol/ } \mathrm{l}^{\mathrm{a}}\end{array}$ & $\begin{array}{l}\text { Fasting serum } \\
\text { triglycerides } \\
\mathrm{mmol} / \mathrm{l}^{\mathrm{a}}\end{array}$ & $\begin{array}{l}\text { Fasting serum } \\
\text { cholesterol } \\
\mathrm{mmol} / \mathrm{I}^{\mathrm{a}}\end{array}$ \\
\hline Diet (13) & 3 & 4 & 2 & 3 & $9.3 \pm 1.2$ & $1.4 \pm 0.2$ & $6.4 \pm 0.3$ \\
Phenformin (9) & 0 & 5 & 4 & 1 & $10.1 \pm 1.4$ & $1.7 \pm 0.2$ & $6.8 \pm 0.2$ \\
Chlorpropamide (13) & 4 & 2 & 3 & 1 & $9.2 \pm 1.3$ & $2.2 \pm 0.5$ & $7.4 \pm 0.9$ \\
\hline
\end{tabular}

( ) No. of patients

a Mean \pm SEM

Table 4. Elastic Modulus (N.m $\left.{ }^{-2} \times 10^{5}\right)$. Mean \pm standard error. Diet (26 measurements) compared with Phenformin (16 measurements) and Chlorpropamide (16 measurements)

\begin{tabular}{lll}
\hline & Phenformin & Chlorpropamide \\
\hline Drug & $1.74 \pm 0.17$ & $1.84 \pm 0.13$ \\
Diet & $1.5 \pm 0.09$ & $1.5 \pm 0.09$ \\
P & NS & $<0.04$ \\
\hline
\end{tabular}

$\mathrm{NS}=$ not significant

higher mean elastic modulus than the diet treated group and both the chlorpropamide and phenformin treated groups contained a significantly greater proportion of abnormal limbs. Since the reason for starting tablet treatment in our patients was the failure of diet alone to control their diabetes it may be that the drug treated groups represent a different population of diabetics more prone to arterial disease. However, while conclusions from this small, retrospective, non-randomised study of leg arteries cannot be extrapolated to the arterial tree as a whole, it is interesting to note that the University Group Diabetic Programme concluded from a randomised propective study that phenformin and tolbutamide caused an excess mortality from cardiovascular disease compared to diet or insulin [16, 17].

Our pilot study demonstrates the value of ultrasonic Doppler velocimeter measurements in the study of arterial disease. It is simple, rapid and noninvasive. Since serial measurements are easily performed, studies of the natural history of the lesion and the effects of treatment, particularly relevant in diabetics, is possible.
Table 5. Comparison of occurrence of abnormal elastic modulus in diet and drug treated patients. Abnormal legs, expressed as a fraction of total

\begin{tabular}{lcc}
\hline & Phenformin & Chlorpropamide \\
\hline Drug & $5 / 16$ & $6 / 16$ \\
Diet & $2 / 26$ & $2 / 26$ \\
P & $<0.05$ & $<0.02$ \\
\hline
\end{tabular}

Acknowledgements. We would like to thank Dr.D.R. Coles, Consultant Physician, and Dr.J.E. Cates, Consultant Physician, for allowing us to study their patients.

\section{References}

1. Jarrett, R.J.: Diabetes, hyperglycaemia and arterial disease. Acta Diabetol. Lat. 8 (Suppl. 1), 7-11 (1971)

2. Kingsbury, K. J.: The relation between glucose tolerance and atherosclerotic vascular disease. Lancet 1966 II, 1374-1379

3. Strandness, D.E., Priest, R.E., Gibbons, G. E.: Combined clinical and pathological study of diabetic and non-diabetic peripheral arterial disease. Diabetes 13, 366-372 (1964)

4. Ferrier, T.H.: Radiologically demonstrable arterial calcification in diabetes mellitus. Australas. Ann. Med. 13, 222-228 (1964)

5. Keen, H., Rose, G., Pyke, D. A., Boyns, D., Chlouverakis, C., Mistry, S.: Blood sugar and arterial disease. Lancet 1965 II, $505-508$

6. Gosling, R.G., King, D.H.: Cardiovascular Applications of Ultrasound R. Reneman (ed.), p. 226. Amsterdam: North Holland 1974

7. Davidson, S., Passmore, R., Brock, J.: Human Nutrition and Dietetics, p. 476, 5th Edition. Edinburgh, London: Churchill Livingstone 1972

8. Brew, W. K. M.: Transitory Changes in Human Arterial Elasticity, Ph.D. Thesis. Dublin: Trinity College 1975 
9. Bergel, D.H.: The dynamic elastic properties of the artery wall. J. Physiol. (Lond.) 156, 458-469 (1961)

10. Gosling, R.G., King, D. H.: Arteries and Veins. A. W. Harcus, L. Adamson, (ed.), p. 90. Edinburgh, London: Churchill Livingstone 1975

11. Wolinsky, H., Glagor, S.: A lammellar unit of aortic medial structure and function in animals. Circ. Res. 20, 99-111 (1967)

12. Newman, D. L., Gosling, R. G., Bowden, N. L. R.: Changes in aortic distensibility and area ratio with the development of atherosclerosis. Atherosclerosis 14, 231-240 (1971)

13. Garcia, M., McNamara, P., Gordon, T., Kannel, W. B.: Vascular and Neurological Changes in Diabetes Mellitus. Suppl. 2 to Advances in Metabolic Disorders. R.A. Camerini-Davalus, H.S. Cole (Ed.), p. 493. New York, London: Academic Press 1973

14. Pell, S., D'Alonzo, C.A.: Some aspects of hypertension in diabetes mellitus. 'J. A. M. A. 202, 104-110 (1967)

15. Keen, H., Jarrett, R. J.: Complications of Diabetes, p. 179. London: Arnold 1975
16. Goldner, M.D., Knatterud, G.L., Prout, T.E.: Effects of hypoglyacaemic agents on vascular complications in patients with maturity onset diabetes. III. Clinical implications of U. G. D. P. Results. J. A. M. A. 218, 1400-1410 (1971)

17. Knatterüd, G.L., Klimt, C. R., Osborne, R. K., Meinert, C. L., Martin, D. B., Hawkins, M. S.: A study of the effects of hypoglycaemic agents on vascular complications in patients with adult onset diabetes. V. Evaluation of phenformin therapy. Diabetes 24 (Suppl. 1), 65-184 (1975)

Received: January 28, 1977,

and in revised form: September 28, 1977

Dr. S. A. Cairns

Tutor in Medicine

Manchester Royal Infirmary

Manchester M13 9WL

England 